\section{Atrial septal defect occluder devices for closure of tracheoesophageal fistulas: are they safe?}

\section{Franco Coppola}

\section{ASL TO4, Italy}

In their recent review on the endoscopic management of tracheoesophageal fistulas [1], Ramai et al cite our article published in Endoscopy [2] and affirm that the cardiac septal umbrella may be used to treat a tracheoesophageal fistula, because it closes the defect and with time the granulation tissue formation induced by the device is able to permanently seal the fistula. They finally assert that the migration of the device we described in our article [2] was due to its incorrect size. I can confirm that the 20 -mm wide umbrella was largely able to completely cover the orifice and at least $6 \mathrm{~mm}$ of normal mucosa around the margins of the fistula. Therefore, as the size of the umbrella was adequate, we assumed that the migration was the consequence of an erosion of the tracheal wall, which was relatively weaker and less perfused than the cardiac muscular wall. This is the main reason why we wanted to point out the possible danger of an off-label use of this device. On the other hand, warnings have been published by the US Food and Drug Administration [3,4], reporting serious erosion events with the Amplatzer Septal Occluder when used according to the on-label indications.

\section{References}

1. Ramai D, Bivona A, Latson W, et al. Endoscopic management of tracheoesophageal fistulas. Ann Gastroenterol 2019;32:1-6.

2. Coppola F, Boccuzzi G, Rossi G, Gaia S, Cosimato M, Recchia S. Cardiac septal umbrella for closure of a tracheoesophageal fistula. Endoscopy 2010;42(Suppl 2):E318-E319.

3. U.S. Food \& Drug Administration. MAUDE Adverse Event Report: AGA Medical Corp Amplatzer transcatheter septal occlude, Report number 2802379, Report date 10/15/2012.

4. DiBardino DJ, McElhinney DB, Kaza AK, Mayer JE Jr. Analysis of the US Food and Drug Administration Manufacturer and User Facility Device Experience database for adverse events involving Amplatzer septal occluder devices and comparison with the Society of Thoracic Surgery congenital cardiac surgery database. J Thorac Cardiovasc Surg 2009;137:1334-1341.

Gastroenterology Unit ASL TO4, Italy

Conflict of Interest: None

Correspondence to: Franco Coppola, Gastroenterology Unit ASLTO4, Corso G. Ferraris 3, 10034 Chivasso TO, Italy,

e-mail: fvcoppola59@gmail.com

Received 18 November 2018; accepted 28 November 2018; published online 7 December 2018

DOI: https://doi.org/10.20524/aog.2018.0333 